\title{
Multi-National Policies for the Universal Service Obligation in the Postal Sector under Entry
}

\author{
MICHAEL A. CREW \\ Center for Research in Regulated Industries, Rutgers University \\ PAUL R. KLEINDORFER *
}

The Wharton School of the University of Pennsylvania and INSEAD

\begin{abstract}
Suppose a multi-national agency can set minimum standards for the postal USO that apply to the countries under its jurisdiction, and that each country is required to comply with, or exceed, these standards. We examine the trade-offs that ensue across countries in designing an efficient USO at the multi-national level when these postal markets are also simultaneously opened to competitive entry. In particular, the paper examines when "subsidiarty dominates" (in which case the multinational regulator should leave the determination of the USO entirely in the hands of national regulators) and when some intervention by the multi-national regulator is desirable.
\end{abstract}

\section{Introduction}

This paper examines an aspect of the Universal Service Obligation (USO) that has not previously been the subject of much attention in research on the USO, namely, the problem of multi-national regulation of the USO. ${ }^{1}$ The multi-national problem arises when a group of countries decide by treaty or other agreement to determine common policies applicable to the entire group of countries. The best current example of this is the European Union (EU). Traditionally, the problem of the USO for postal services has been examined only in the context of a single country as in the normative analysis presented in Crew and Kleindorfer (1998) (C-K).

$\mathrm{C}-\mathrm{K}$ pose a single-country model in which entry is allowed, while the incumbent postal operator (PO) is faced with a USO, modeled as the obligation to provide ubiquitous service at a uniform price (and implicitly also subject to service quality constraints) for all services

\footnotetext{
* Contact Author. Anheuser-Busch Professor of Management Science (Emeritus), The Wharton School of the University of Pennsylvania; and Distinguished Research Professor, INSEADBlvd de Constance, 77305 Fontainebleau, France. Email: kleindorfer@wharton.upenn.edu. An earlier version of this paper was presented at the 4th Postal Conference "Regulation, Competition and Universal Service in the Postal Sector," IDEI, Toulouse, March 16-17, 2006. The authors acknowledge with thanks the comments of the participants and especially of Etienne Billette de Villemeur, Helmuth Cremer and Jacques Crémer.

${ }^{1}$ A national regulator could also face this problem where standards vary regionally or locally and where a minimum standard is required to be met at all levels. See Crémer and Palfrey (2000) for a discussion and analysis of some of the problems arising in this general context.
} 
covered by the USO. C-K identify several key tradeoffs in their analysis of the USO. First, pricing uniformity reduces transaction costs for customers and for the PO for single-piece mail, but it also may induce inefficient entry. Second, assuming the PO is to float on its own bottom, without subsidies, the presence of fixed costs and uniform pricing create incentives for cream skimming, which may lead to financial difficulties for the PO. ${ }^{2}$ Third, if financing of the USO is accomplished by reserving the exclusive right to provide certain services to the PO (that is, by retaining the traditional "reserved area"), then the USO financing problem is further confounded with efficiency problems associated with monopoly provision, including the loss of competitive innovation and product portfolio expansion, together with the problem of trying to regulate the prices, profits and production efficiency of the resulting PO. Thus, additional tradeoffs may arise in the joint design of the reserved area and the USO. The essence of these tradeoffs is that expanding the reserved area allows for a broader scope of USO to be imposed, while still maintaining financial viability of the PO. However, the reduced transaction costs for customers associated with an expanded USO, financed by an expanded reserved area, come at the cost of lower benefits from entry. C-K analyze the welfare-optimal design problem associated with balancing these costs and benefits. They show that the optimal scope of the USO and the reserved area depend on the magnitude of transaction cost savings from the USO, the benefits of differentiated products, the efficiency of potential entrants relative to the PO, and several other cost and demand drivers.

Others have examined the nature of the USO in practice, including Ambrosini, Boldron and Roy (2006) and Finger, Alyanak and Rossel (2005). Ambrosini et al describe the varied approaches taken to defining the scope of the USO in 19 countries from around the world. While there are many common elements to the USOs in the POs surveyed, there are also interesting differences, with approaches differing according to the scope of products included, the nature of service quality requirements such as delivery frequency and accessibility to postal counters, and the pricing constraints on affordability and uniformity applied. For example, some countries define the USO for the PO to include very precise and extensive requirements for collection frequency and post office locations, while others have less stringent requirements. Some countries require pricing uniformity extensively across product offerings, while others apply uniform pricing on a more limited basis. Access pricing and protocols may or may not belong to the USO, and many other countryspecific differences arise when considering the nature of regulation applied to the PO. In general, while the USO remains a central feature of POs around the world, different countries have developed variations on both the definition of the USO, as well as regulatory mechanisms to assure compliance.

The USO is likely to be of even greater interest in the future, since many countries are following the road to liberalization. Together with technological change and electronic substitution, liberalization policies promoting competitive entry could put the traditional USO at risk. First, technological competition has provided substitutes for and reduced demand for letter mail. This results in a potential increase in a PO's unit costs if it loses some of the benefits of scale economies because of the lower output. Meanwhile, the fixed

\footnotetext{
${ }^{2}$ These financial difficulties were examined in a series of follow-on papers by $\mathrm{C}-\mathrm{K}$ and others, which examined conditions under which the PO's viability could be assured under entry. The most recent paper in this series is Crew and Kleindorfer (2006), which the reader can consult for an overview of preceding work in this vein. Other recent work on financial viability includes Cohen et al (2000, 2004), d'Alcantara and Amerlynck (2006) and De Donder et al (2002).
} 
costs of the USO continue. Second, liberalization implies changes that eliminate or significantly reduce the POs' reserved area, and this means taking away the primary means through which the USO has been funded to date.

In the absence of a reserved area, the feasible options for financing the USO burden in the face of entry consist generally of a combination of greater commercial freedom for the PO, with the increased commercial operations and competition implied by this, and a reduction in the scope of the USO. Greater commercial orientation can take a number of forms, resulting in increased cost control, more flexible pricing and the ability to adjust the product line with reduced regulatory oversight (see Crew and Kleindorfer (2006) for details). Reducing the burden of the USO prima facie appears to be an effective way of enabling as PO to survive when facing entry, since relaxing the uniformity constraint (in terms of delivery frequency, service quality and/or in pricing) ${ }^{3}$ of the USO should allow the PO to remain viable under a broader set of demand, cost and entry scenarios than it could under more stringent uniformity constraints. For example, Haldi and Merewitz (1997), Cohen et al (2000), Haldi and Schmidt (2002) and Finger et al (2005) discuss the benefits in decreasing the USO burden under entry by making significant changes in the service standards, with high cost areas receiving significantly lower service standards (for example, three-days a week delivery instead of five or six). The extent of the differences in quality needed to achieve measurable reductions in the USO burden may again differ across countries.

Such considerations have received considerable attention in the literature but the focus has been on single-country markets. However, in the EU this is changing with the postal Directives of 1997, 2002 and 2008, and the movement toward full market opening of postal markets in all of the 27 Member States by the year 2011-2013. The postal Directives establish for all Member States an EU-wide minimum standard for their USO, where individual countries in the EU have adopted (see Ambrosini et al. (2006)) broader USOs than the EU requirements (which essentially call for five day a week deliveries, uniform tariffs, ${ }^{4}$ and reasonable accessibility and affordability of postal services). The debate on USO policy under the impending liberalization will remain a central focus in the EU in view of the Third Postal Directive recently approved by the European Parliament in February, 2008. ${ }^{5}$ The Third Directive calls for maintaining the EU-level minimum USO at its current level, but the wording of the Directive still leaves some flexibility to member

\footnotetext{
${ }^{3}$ The standard argument for uniform pricing, for example, Crew and Kleindorfer (1998), is that it reduces the transaction costs for customers. This argument now applies only to small customers, where the transaction costs resulting from non-uniform letter pricing would be significant. For large customers, transaction cost savings arising from uniform pricing are not important because of advances in information technology. See Finger et al (2005), Crew and Kleindorfer (2007), and Pintsov et al (2007) for a discussion of differences between bulk mail and single-piece mail USO requirements and the implications for the design of an efficient USO. However, uniform pricing often survives, usually without good reason, in existing postal tariffs for business mailers in the form of uniform avoided-cost discounts off end-to-end prices for access tariffs and in zonal averaging.

${ }^{4}$ It should be noted, however, that the application of a uniform tariff does not exclude the right of the USP to conclude individual agreements on prices with customers, and such agreements are evident, in particular, in the area of access pricing. For details on European developments and the USO, see the recent study on the impact of market opening in the European Union by PricewaterhouseCoopers (2006).

${ }^{5}$ The European Commission Postal Directive (Directive 97/67/EC as amended by Directive 2002/39/EC) envisaged the full opening of the EU postal market to competition by 1 January 2009. The Third Postal Directive, approved on February 20, 2008, requires full opening in most member states by 2011 and in all states by 2013. See, For details, see http://ec.europa.eu/internal_market/post/facts_en.htm
} 
states to determine, how the USO will ultimately evolve. The result is that some member states in the EU are pressing for a continuation of the historical USOs in their respective countries, while others are calling for a significant reduction in the USO after liberalization. ${ }^{6}$ Interpreting the multi-national definition of the USO in the EU 3rd Postal Directive will therefore be an important determinant of the ultimate USO policies adopted in each member state.

It is important to note why multi-national regulation, rather than strictly national regulation, of the USO is at all an important policy matter. After all, there are no apparent externalities across most national postal markets, so why not leave the choice of the USO entirely to national governments? Taking the EU as an example, the answer is that the key objective of multi-national postal policy has been to create a pan-European internal market for postal services, with free entry into any product category or region. This procompetition policy of EU postal policy has been evolving over the past 15 years, and culminating in full market opening in the 3rd Postal Directive of 2008. To accomplish this, however, requires that the standards for the USO be precisely defined across all member states. If this is not done with care, then confusion and delays can be expected, as various stakeholders in the postal sector (labor, households, large mailers, investors) attempt to have the USO at the national level defined to serve their own interests. For example, organized labor may push for a very high USO in order to have a better case for maintaining high employment levels and generating subsidies from the state to support the USO. Large mailers and potential entrants, by contrast, may wish to see the development of more vibrant competition. This could face significant barriers if a USO of greater scope were maintained, which could be used at every turn to legitimate policies to assure the continued dominant position of the incumbent PO.

Against this background, we propose to analyze a simple model of a multi-national USO, which is a stylized version of the EU situation, in which a multi-national agency sets minimum policy for the USO, with member countries then free to set a "higher" level of USO. We analyze the case in which there is some historical or other reason such that each country is committed to a certain level of USO. In section 2, we develop a simple model to represent the choice of the scope of the USO in a particular national market. We note the details of how entry and the choice of the USO will interact in a liberalized market to influence welfare and profits of the Universal Service Provider (USP), which is assumed to be the incumbent PO. The entry considered is potentially from other POs, as well as from entrants. Motivated by these single-country results, we then consider in section 3 the aggregate profit and welfare consequences for a larger set of countries in their choice of minimum standards for the USO to be applied across these countries. We derive some results for this general case, showing when the multi-national regulator should set a USO exceeding that which some country would have chosen if it were not subject to multinational regulation. Section 4 discusses some of the possible conclusions from this analysis. As with other policy issues related to the USO, robust conclusions concerning optimal multi-national policies are not available from theory alone. Rather, efficient multinational USO policies depend on country characteristics, so that an empirical assessment

\footnotetext{
${ }^{6}$ See Finger et al (2005) for a discussion of the current EU requirements for the USO and for some of the reasons for reconsidering and reducing the scope of the USO as liberalization approaches. It should be noted, of course, that there are many other issues beyond the USO policy that must also be determined as the EU moves to liberalization, including issues relating to regulation and to access policies.
} 
will be required to inform the design of multi-national USO policies. The nature of the multi-national assessment required will be briefly discussed in concluding the paper.

Our results can be summarized as follows. First, we consider a model in which entrants can capture market share from a hitherto monopoly incumbent in a single liberalized postal market. The Incumbent faces a USO that consists of affordability constraints, uniform pricing and requirements for establishing a network with a certain density of postal counters. The scope of these USO requirements is the subject of the economic design problem analyzed. We derive first-best and Ramsey (breakeven constrained) benchmarks for the optimal scope of USO, and show how this scope depends on the tradeoffs between the transaction cost savings of customers, who benefit from the USO and the costs and benefits of entry under the constrained USO design. We then show the conditions under which it is efficient to set minimal standards at a multi- national level, allowing countries to determine their own scope of USO. We note that the primary driver of the outcome that "subsidiarty is efficient" is the presumption (imposed in our model) that the incumbent PO in each national state covered by the multi-national USO regulation desires only minimal USO requirements. The rationale provided in the modeling framework adopted is that the incumbent PO is a for-profit organization, which therefore would foresee constraints on its operational and pricing decisions (whether from the USO or otherwise) as an unwanted intrusion on its commercial freedom. Since there are several other models and motivations that may be considered realistic for national POs vis-à-vis USO policy, we consider some of the possible variations on this theme in the final section of the paper.

\section{USO policy and welfare for a single country}

Consider a set of $\mathrm{N}=\{1, \ldots, \mathrm{n}\}$ countries. Each country has a national $\mathrm{PO}$, which is simultaneously the Universal Service Provider (USP). In this section, we consider one of the national markets and analyze the consequences for welfare and financial viability of the USO imposed in the country, whether the USO arises from a multi-national regulator for $\mathrm{N}$ or from the country's national regulator for some i $\varepsilon \mathrm{N}$. We will consider only a single product ("letters") and a situation in which the USP is required to service all addresses in the country (ubiquitous service).

To capture the essence of the USO, we consider three typical constraints embodied in the USO: 1) a uniform price for all delivery zones; 2) a requirement for locating post office outlets according to population density in each zone; and 3) an affordability constraint, taken here to be a zero-profit constraint on prices of USO products. ${ }^{7}$ The intent here is to capture the spirit of the USO as a constraint on USP services that may make it more difficult for the USP to compete (especially for high-margin products in the low-cost delivery areas), but which may, nonetheless, be valuable for customers in terms of reduced transaction costs, ubiquity of coverage or other potentially valued service attributes.

\footnotetext{
${ }^{7}$ There have been several proposals recently to relax the uniform pricing constraint (especially on letters) of the traditional USO (for example, Crew and Kleindorfer (2007) and Pintsov et al (2007)). These proposals are directed not only toward single-piece letters, but also toward bulk mailings originating from large mailers many of which are subject to uniform tariffs resulting from avoided-cost worksharing discounts. In addition, proposals (for example, Felisberto et al (2006)) to charge for "the final mile" (rather than to a more accessible centralized mailbox location) are also a move away from uniform pricing. Most of the earlier discussion on varying the scope of the USO focused on relaxing service quality for high-cost delivery areas.
} 
To keep matters simple, we assume completely inelastic demand, with demand for zone $\mathrm{t} \varepsilon[0, \mathrm{~T}] \subset \mathfrak{R}^{+}$given by $\mathrm{D}(\mathrm{t})$. We denote the reservation price/value per letter by $\mathrm{v}$. In keeping with the notion of full market opening, we assume no reserved area for the incumbent and Bertrand competition between the USP and a set of entrants some of which may be POs from other countries. We assume that entrants are sufficiently numerous and homogeneous that they can be treated as a competitive fringe in each country.

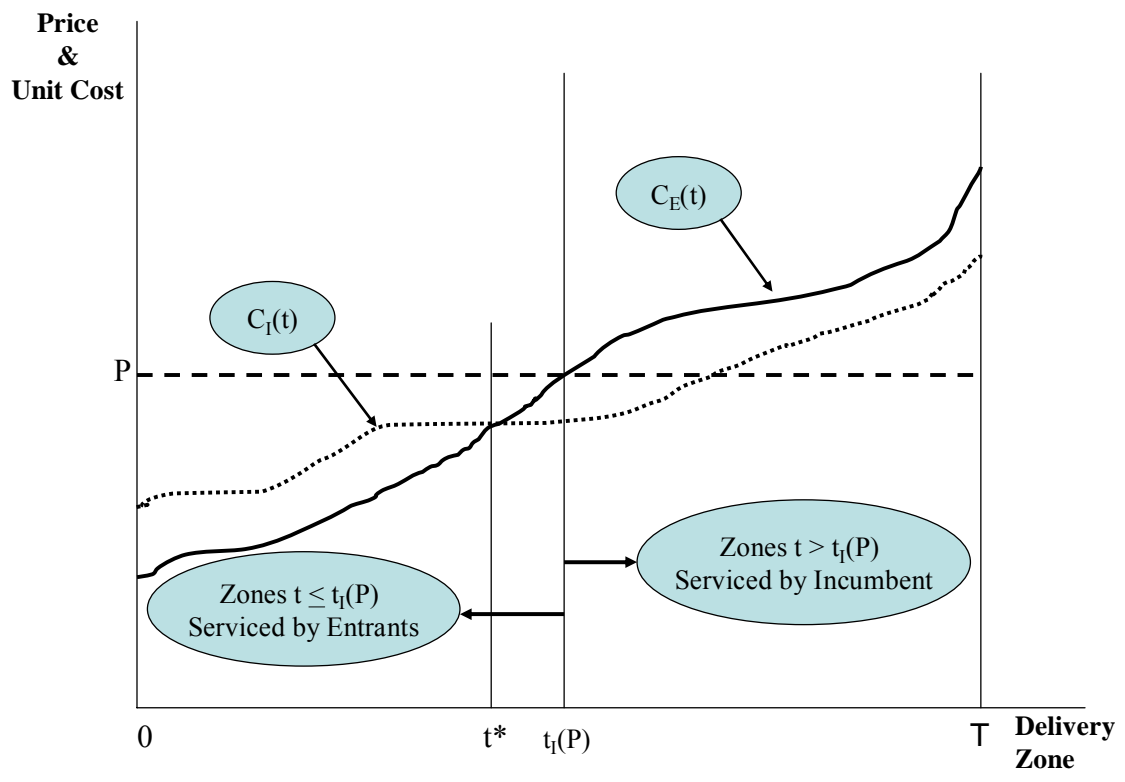

Figure 1: Illustrating Scope of USO and Entry

Figure 1 illustrates the problem, following C-K (2000). The horizontal axis represents the different delivery zones of the country, arranged in increasing order of entrant's unit costs (we show only the minimum such cost across all entrants, as this is the only cost that matters in determining market shares). The vertical axis is price (or unit cost). The unit costs of entrants is the curve $C_{E}(t)$, while for the incumbent it is $C_{I}(t)$, both of which are assumed continuous and strictly increasing on $[0, \mathrm{~T}]$. To make matters interesting, it is assumed that $\mathrm{C}_{\mathrm{E}}(0)<\mathrm{C}_{\mathrm{I}}(0)$, so that entrants enjoy a cost advantage in some of the low-cost areas. Price is uniform at $\mathrm{P}_{\mathrm{I}}$ for all delivery zones under the USO. Since delivery zones are indexed in increasing order of $\mathrm{C}_{\mathrm{E}}(\mathrm{t})$, the intersection (if there is one) between the uniform price $\mathrm{P}=\mathrm{P}_{\mathrm{I}}$ and $\mathrm{C}_{\mathrm{E}}(\mathrm{t})$ defines the point $\mathrm{t}_{\mathrm{I}}(\mathrm{P})$, to the left of which entrants will capture all mail and to the right of which the incumbent USP will be the supplier. ${ }^{8}$

The USO requirement that post offices be located in reasonable proximity to the population is assumed to give rise to (say, annual) fixed costs proportional to the required number $\mathrm{M}$ of post offices. Let " $\mathrm{m}$ " be the number of post offices required per unit of

\footnotetext{
${ }^{8}$ More complex models have been developed after C-K (2000) which show outcomes that have the incumbent and entrants sharing delivery of mail on routes, rather than the simpler model here that shows an all or none outcome in which either a delivery zone is fully supplied by entrants or fully supplied by the incumbent. These richer models take a customer-specific focus or introduce imperfect product differentiation. See, Crew and Kleindorfer $(2001,2006)$ for a discussion.
} 
demand and denote the (annual) cost per post office by $\gamma$. Then the total cost of requiring $\mathrm{m}$ post offices per unit of demand is:

(1) $\quad F(u)=\gamma M=\gamma m \int_{0}^{T} D(t) d t=u \int_{0}^{T} D(t) d t$

where $\mathrm{u}=\gamma \mathrm{m} \in \mathfrak{R}^{+}$will be taken to be the decision variable on the density of post office coverage. Note that "u" captures both the density of post offices (m), as well as the scope of services offered at each post office $(\gamma)$. It is one element defining the scope of the USO, the other elements being uniformity of price and affordability. The affordability constraint for the USO is understood here to be the least price (if one exists) that assures breakeven operations for the incumbent while meeting pricing uniformity and the specified USO represented by $\mathrm{u}$ in (1). ${ }^{9}$ Our assumptions give rise to the following two identities characterizing price $\mathrm{P}$ and USP profits $\Pi(\mathrm{P}, \mathrm{u})$ :

(2) $\mathrm{C}_{\mathrm{E}}\left(\mathrm{t}_{\mathrm{I}}\right)=\mathrm{P} \Rightarrow \mathrm{t}_{\mathrm{I}}(\mathrm{P})=\mathrm{C}_{\mathrm{E}}^{-1}(\mathrm{P})$

(3) $\Pi(P, u)=\int_{t_{I}(P)}^{T}\left(P-C_{I}(t)\right) D(t) d t-F(u)=0$

We do not explore here issues of the Graveyard Spiral (Crew and Kleindorfer, 2000), and so we assume that the required $\mathrm{u} \in \mathfrak{R}^{+}$is not so onerous as to preclude a solution to (3), moreover, that this solution occurs while gross profits $\Pi(\mathrm{P}, \mathrm{u})$ are increasing in $\mathrm{P}$ (that is, a price $\mathrm{P}(\mathrm{u})$ less than the profit-maximizing price solves (3)). Given this, it is easily established under some regularity conditions stated below that the solution $\mathrm{P}(\mathrm{u})$ to $(3)$ is unique and monotonic increasing in $u$ (see Lemma 1, Appendix).

To capture the benefits of the USO, we assume that consumer transaction costs (per letter) in accessing the postal network are proportional to the average distance to a post office, ${ }^{10}$ which we assume is then inversely related to the total number of such post offices $\mathrm{M}$. Thus, letting $\mathrm{\kappa} / \mathrm{M}$ be the cost per letter, then the total transaction costs $\mathrm{A}(\mathrm{u})$ when the scope of the USO is given $u \varepsilon \mathrm{U}$ are given by

(4) $\quad \mathrm{A}(\mathrm{u})=\frac{\kappa}{\mathrm{M}} \int_{0}^{\mathrm{T}} \mathrm{D}(\mathrm{t}) \mathrm{dt}=\frac{\kappa}{\mathrm{m} \int_{0}^{\mathrm{T}} \mathrm{D}(\mathrm{t}) \mathrm{dt}} \int_{0}^{\mathrm{T}} \mathrm{D}(\mathrm{t}) \mathrm{dt}=\frac{\gamma \kappa}{\gamma \mathrm{m}}=\frac{\mathrm{K}}{\mathrm{u}}$

\footnotetext{
${ }^{9}$ We will see below that imposing the less constraining requirement that $\Pi(\mathrm{P}, \mathrm{u}) \geq 0$ leads at the Ramsey optimal solution to (3). Thus, in the context of the present model, assuming (3) holds as an equality is without loss of generality from a welfare perspective.

${ }^{10}$ In Crew and Kleindorfer (1998), we also considered transaction cost savings arising from uniform pricing by the PO. These are neglected here. As noted above, such savings would only be applicable in any case to small customers using single-piece mail services.
} 
where $\mathrm{K}=\gamma \kappa$ is a proportionality factor measuring the value of time and inconvenience of accessing a post office.

From (1)-(4), we can express the welfare associated with a given USO policy in the traditional form of the (unweighted) sum of consumer and producer surpluses:

$$
W(P, u)=v \int_{0}^{T} D(t) d t-\int_{0}^{t_{I}(P)} C_{E}(t) D(t) d t-\int_{t_{I}(P)}^{T} C_{I}(t) D(t) d t-F(u)-A(u)
$$

Before proceeding, we need some regularity conditions on costs and demands, which amount to assuming that the incumbent is disadvantaged in the low-cost areas, but has cost advantages in the high-cost delivery zones, and that demand declines sufficiently quickly as one moves from low-cost to high-cost zones. Specifically, we assume:

\subsection{Regularity conditions (RC)}

RC(i): $C_{E}(t)$ and $C_{I}(t)$ are differentiable and strictly increasing on $[0, T]$, with $\mathrm{C}_{\mathrm{I}}(0)>$ $\mathrm{C}_{\mathrm{E}}(0)$ and $\mathrm{C}_{\mathrm{I}}(\mathrm{T})<\mathrm{C}_{\mathrm{E}}(\mathrm{T})$, and with a unique $\mathrm{t}=\mathrm{t}^{*} \varepsilon[0, \mathrm{~T}]$ such that $\mathrm{C}_{\mathrm{I}}\left(\mathrm{t}^{*}\right)=\mathrm{C}_{\mathrm{E}}\left(\mathrm{t}^{*}\right)$;

$\mathrm{RC}(\mathrm{ii})$ : $\mathrm{D}(\mathrm{t})$ is positive on $[0, \mathrm{~T}]$;

$R C\left(\right.$ iii): $\left[C_{I}(t)-C_{E}(t)\right] D(t)+\frac{d C_{E}(t)}{d t} \int_{t}^{T} D(\tau) d \tau$ is strictly decreasing on [t*, $\left.T\right]$, where $t^{*}$ is the unique crossover point specified in condition RC(i)).

Given $\mathrm{RC}$, the solution $\left(\mathrm{P}_{\mathrm{W}}, \mathrm{u}_{\mathrm{W}}\right)$ to the first-best problem of maximizing (5) over nonnegative prices $\mathrm{P}$ and scope of USO $\mathrm{u}$ is obtained directly from the relevant first order conditions as:

(6) $\mathrm{t}_{\mathrm{I}}\left(\mathrm{P}^{\mathrm{W}}\right)=\mathrm{t}^{*}$ so that $\mathrm{C}_{\mathrm{E}}\left(\mathrm{t}_{\mathrm{I}}\left(\mathrm{P}^{\mathrm{W}}\right)\right)=\mathrm{C}_{\mathrm{I}}\left(\mathrm{t}_{\mathrm{I}}\left(\mathrm{P}^{\mathrm{W}}\right)\right) ; \mathrm{u}^{\mathrm{W}}=\sqrt{\frac{\mathrm{K}}{\mathrm{Q}}}$

where total (say, annual) volume $\mathrm{Q}$ is defined as

(7) $Q=\int_{0}^{T} \mathrm{D}(\mathrm{t}) \mathrm{dt}$

Intuitively, the first-best price is set to ensure that Entrants serve the low-cost zones $t<$ $\mathrm{t}_{\mathrm{I}}\left(\mathrm{P}^{\mathrm{W}}\right)=\mathrm{t}^{*}$, where $\mathrm{C}_{\mathrm{E}}(\mathrm{t})<\mathrm{C}_{\mathrm{I}}(\mathrm{t})$, and the Incumbent serves all those zones $\mathrm{t}>\mathrm{t}_{\mathrm{I}}\left(\mathrm{P}^{\mathrm{W}}\right)$ for which it has the cost advantage (note that there is a single cross-over point $t^{*}=t_{I}\left(P^{W}\right)$ by $\mathrm{RC}(\mathrm{i})$ ). Given the separability of $\mathrm{W}(\mathrm{P}, \mathrm{u})$ in $\mathrm{P}$ and $\mathrm{u}$, the first-best solution for $\mathrm{u}$ is easily obtained as the solution $\mathrm{u}^{\mathrm{W}}$ shown in (6) which minimizes the sum of USO fixed costs $\mathrm{F}(\mathrm{u})$ 
and transaction costs $\mathrm{A}(\mathrm{u})$. From (6) and $\mathrm{RC}$, it should be clear that the first-best solution entails losses for the incumbent, since setting price according to (6) will ensure that the incumbent makes losses on every zone it serves (that is, for every $\mathrm{t}>\mathrm{t}_{\mathrm{I}}\left(\mathrm{P}^{\mathrm{W}}\right)$ ). As this is not a sustainable arrangement without subsidies, ${ }^{11}$ we turn to the Ramsey problem, namely, the maximization of W in (5) subject to breakeven operations for the USP. Some of the properties of the Ramsey solution are stated in Proposition 1.

\subsection{Proposition 1:}

Assume the Regularity Conditions RC hold, and consider the Ramsey problem:

$$
\operatorname{Max}\langle\mathrm{W}(\mathrm{P}, \mathrm{u}) \mid \Pi(\mathrm{P}, \mathrm{u}) \geq 0, \mathrm{P} \geq 0, \mathrm{u} \geq 0\rangle
$$

Define $\overline{\mathrm{u}}=\Pi^{*} / \mathrm{Q}$, where $\Pi^{*}=\operatorname{Max}\langle\Pi(\mathrm{P}, 0) \mid \mathrm{P} \geq 0\rangle$ and $\mathrm{Q}$ is total quantity, and assume that $\Pi^{*}>0$. Then, $\mathrm{W}(\mathrm{P}, \mathrm{u})$ is well defined and continuous on $U=[0, \overline{\mathrm{u}}]$. Moreover, a solution $\left(\mathrm{P}^{*}, \mathrm{u}^{*}\right)$ to $(8)$ exists and satisfies:

$$
\mathrm{u}^{*} \in \mathrm{U}, \quad \mathrm{u}^{*} \leq \operatorname{Min}\left[\sqrt{\frac{\mathrm{K}}{\mathrm{Q}}}, \frac{\Pi^{*}}{\mathrm{Q}}\right] \leq \mathrm{u}^{\mathrm{w}} ; \Pi\left(\mathrm{P}^{*}, \mathrm{u}^{*}\right)=0 ; \mathrm{P}^{*}>\mathrm{P}^{\mathrm{w}}
$$

Proposition 1 is proved in the Appendix. Note that, as expected, the Ramsey solution entails a smaller USO and a higher price than the first-best solution. Assuming RC, the first three terms in (5) can be shown to be decreasing as the scope of the USO increases, while the (negative of the) final two terms (reflecting the fixed cost of the USO and the transaction costs of customers in accessing USO services) first decrease and then increase, so that a trade-off ensues between the cost of financing the USO and its benefits. The intuitive trade-off captured in these results is that the larger the burden of the USO (either because its scope is increased or because the underlying cost drivers for the PO increase), the larger must be the PO's breakeven price $\mathrm{P}^{*}$ and the larger the resulting market share of entrants. The bounds in (9) reflect this trade-off, and show that the maximum scope of the USO under Ramsey pricing is bounded by the transaction costs per unit demand and the profit per unit demand. The reader interested in greater detail on the nature of the tradeoffs should consult the proof of Proposition 1 in the Appendix.

As a final note on this model, let us consider the welfare impact of entry itself. Regarding the welfare function (5), it is straightforward to compare the entry and no entry cases for any $(\mathrm{P}, \mathrm{u})$ pair. The "no entry" or monopoly case is obtained by setting $\mathrm{t}_{\mathrm{I}}(\mathrm{P})=0$. Thus, comparing entry $=\mathrm{E}$ and monopoly $=\mathrm{M}$, we see that the welfare difference between the two cases is given by:

\footnotetext{
${ }^{11}$ We discuss in Section 4 some of the additional issues in the USO design problem that arise when subsidies are considered.
} 
(10) $W_{E}(P, u)-W_{M}(P, u)=\int_{0}^{t_{I}(P)}\left[C_{I}(t)-C_{E}(t)\right] D(t) d t$

With an eye on Figure 1, this difference could be positive or negative depending on the structure of $\mathrm{C}_{\mathrm{I}}(\mathrm{t})$ and $\mathrm{C}_{\mathrm{E}}(\mathrm{t})$. In particular, if $\mathrm{C}_{\mathrm{E}}(\mathrm{t})$ is only slightly less than $\mathrm{C}_{\mathrm{I}}(\mathrm{t})$ for $\mathrm{t}<\mathrm{t}^{*}$, but $t^{*}$ is considerably less than $t_{I}(P)$, perhaps because of a significant USO burden, then entry would reduce welfare at the given $(\mathrm{P}, \mathrm{u})$ pair. Assuming that the analysis began at a breakeven monopoly price, entry would also occasion a further increase in this price for any given USO level, leading at the Ramsey solution to a potential further decrease in welfare from inefficient entry.

\section{Design of the multi-national USO}

Now consider optimal multi-national USO design for a set of $\mathrm{N}=\{1, \ldots, \mathrm{n}\}$ countries. Per the previous section, we assume that each country has a national PO, which is simultaneously the Universal Service Provider (USP). We assume throughout that no subsidies are allowed or required for the PO to remain financially viable. In this section, we do not explicitly impose the "affordability" condition that the USP is subject to a zeroprofit constraint (although such a constraint is one of several types of constraints that could be imposed in the more general theory that follows). Instead, we assume the USP is a "profit maximizer", but subject to various constraints, whose stringency varies as the scope of USO imposed varies. ${ }^{12}$ Denote the scope of the USO by the scalar $\mathrm{u} \varepsilon \mathrm{U}$, where $\mathrm{U} \subset \mathfrak{R}$ is assumed to be some non-empty closed interval of the real line, and where the usual order in $\mathfrak{R}$ is assumed to reflect the scope of the USO. Each country "i" is assumed to have a USO standard $\mathrm{u}_{\mathrm{i} 0} \varepsilon \mathrm{U}$, such that USO policies implemented by $\mathrm{USP}_{\mathrm{i}}$ must satisfy $\mathrm{u} \geq \mathrm{u}_{\mathrm{i} 0}, \mathrm{i} \varepsilon$ N.

Denote the set of decisions that the USP must make as $\mathrm{x} \varepsilon \mathrm{X}$, where $\mathrm{X}$ is assumed to be a closed subset of $\Re^{\mathrm{n}}$. Such decisions would include pricing, product attributes and operational decisions. Let $\Gamma_{\mathrm{i}}(\mathrm{u})$ be an upper semi-continuous point-to-set mapping $\Gamma_{\mathrm{i}}: \mathrm{U} \rightarrow \mathrm{C}(\mathrm{X})$ into the non-empty and compact sets of $\mathrm{X}$, where $\Gamma \mathrm{i}(\mathrm{u})$ is to be interpreted as the set of feasible choices in $\mathrm{X}$ for $\mathrm{USP}_{\mathrm{i}}$ when the prevailing USO in country i $\varepsilon \mathrm{N}$ is $\mathrm{u}$.

To capture the fact that the USO is a constraint on the USP's choices, $\Gamma_{i}(u)$ is assumed monotonic non-increasing, in the sense that:

(11) $\left[\mathrm{u} \leq \mathrm{u}^{\prime}\right] \Rightarrow\left[\Gamma_{\mathrm{i}}(\mathrm{u}) \supseteq \Gamma_{\mathrm{i}}\left(\mathrm{u}^{\prime}\right)\right], \forall \mathrm{u}, \mathrm{u}^{\prime} \in \mathrm{U}$

Denoting profits for $\mathrm{USP}_{\mathrm{i}}$ by $\Pi_{\mathrm{i}}$, assume that $\Pi_{\mathrm{i}}: \mathrm{X} \times \mathrm{U} \rightarrow \mathfrak{R}$ is continuous, and consider the derived optimal profits $\pi_{\mathrm{i}}: U \rightarrow \mathfrak{R}$ for $\mathrm{UPS}_{\mathrm{i}}$, defined for a specified USO $\mathrm{u} \in \mathrm{U}$ as:

\footnotetext{
${ }^{12}$ As Etienne Billette de Villemeur has pointed out to us, the same framework could capture other objectives of the USP, such as revenue maximization or some measure of managerial discretion. The key issue in what follows is that the USP has enough political clout to ensure that the scope of the USO will not exceed the maximum of the historical USO in country $i$ and that imposed by the multi-national regulator.
} 
(12) $\pi_{\mathrm{i}}(\mathrm{u})=\operatorname{Max}\left\langle\Pi_{\mathrm{i}}(\mathrm{x}, \mathrm{u}) \mid \mathrm{x} \in \Gamma_{\mathrm{i}}(\mathrm{u})\right\rangle$

The function $\pi_{\mathrm{i}}$ is well defined and continuous because of our assumptions on $\Pi_{\mathrm{i}}$ and $\Gamma_{\mathrm{i}}(\mathrm{u})$. Moreover, because $\Gamma_{\mathrm{i}}(\mathrm{u})$ is monotonic non-increasing, it is easily verified that $\pi_{\mathrm{i}}$ is also monotonic non-increasing on U. To avoid uninformative technical discussions, assume further that the solution to (12) is unique for any given $u$ (which it would be, for example, if $\Pi_{\mathrm{i}}$ is strictly quasi-concave in $\mathrm{x}$ and $\Gamma_{\mathrm{i}}(\mathrm{u})$ is convex for each $\left.\mathrm{u} \varepsilon \mathrm{U}\right)$, with the optimal solution $\mathrm{x}_{\mathrm{i}}^{*}(\mathrm{u})$ defined through the equality $\Pi_{\mathrm{i}}\left(\mathrm{x}_{\mathrm{i}}^{*}(\mathrm{u}), \mathrm{u}\right)=\pi_{\mathrm{i}}(\mathrm{u})$.

As in the previous section, define the welfare function for market i $\varepsilon \mathrm{N}$ as the (possibly weighted) sum of consumer and producer surpluses, and denote this as $\mathrm{W}_{\mathrm{i}}(\mathrm{x}, \mathrm{u})$ for any given $(\mathrm{x}, \mathrm{u}) \in \mathrm{X} \times \mathrm{U}$, and assume it to be continuous. As with profits, define the derived welfare function $\mathrm{w}_{\mathrm{i}}(\mathrm{u})=\mathrm{W}_{\mathrm{i}}\left(\mathrm{x}_{\mathrm{i}}^{*}(\mathrm{u}), \mathrm{u}\right)$, that is $\mathrm{w}_{\mathrm{i}}(\mathrm{u})$ is aggregate welfare $\mathrm{W}_{\mathrm{i}}(\mathrm{x}, \mathrm{u})$ for market i $\varepsilon N$ evaluated at the operating decisions $x_{i}^{*}(u)$ chosen by USP $P_{i}$ in (12).

Let us now formulate the multi-national USO design problem. To state this problem, we assume that each USP $_{i}$ is able to negotiate with country i's regulators such that the actual USO implemented by USP $_{i}$ is the maximum of the multi-national USO and the country-specific minimum $\mathrm{u}_{\mathrm{i} 0}$. Since $\pi_{\mathrm{i}}$ is non-increasing, there would be no reason for $\mathrm{USP}_{\mathrm{i}}$ to want to do more than the minimum, but the (national) regulator may be inclined to require higher than the minimum USO if consumer surplus were strongly increasing beyond the historical USO $\mathrm{u}_{\mathrm{i} 0}$; so this is clearly an assumption. ${ }^{13}$

A1: (Minimal Response by $\mathrm{USP}_{\mathrm{i}}$ ): For any given multi-national standard $\mathrm{u} \varepsilon \mathrm{U}$ for the USO, the implemented standard in country $\mathrm{u}_{\mathrm{i}} \varepsilon \mathrm{U}$ will be $\mathrm{u}_{\mathrm{i}}=\max \left[\mathrm{u}, \mathrm{u}_{\mathrm{i} 0}\right]$.

From A1, if a multi-national USO of $u \varepsilon U$ is chosen, then $u_{i}=\max \left[u, u_{i 0}\right]$ will be implemented in country $\mathrm{i}$, leading to aggregate welfare of wi(max $\left.\left[\mathrm{u}, \mathrm{u}_{\mathrm{i} 0}\right]\right)$. Given $\mathrm{A} 1$, the USO design problem of interest can be stated as follows:

\subsection{Multi-National USO Design Problem}

(13) $\operatorname{Max}\left\langle\sum_{i \in N} \mathrm{w}_{\mathrm{i}}\left(\max \left[\mathrm{u}, \mathrm{u}_{\mathrm{i} 0}\right]\right) \mid \mathrm{u} \in \mathrm{U}\right\rangle$

A2: (Unimodal Welfare Function): Assume that the welfare function $\mathrm{w}_{\mathrm{i}}$ is unimodal (that is, has exactly one local maximum), i $\varepsilon \mathrm{N}$.

Assuming A2, and noting the continuity of $\mathrm{w}_{\mathrm{i}}$, we denote the maximum of $\mathrm{w}_{\mathrm{i}}$ over the set of feasible $u$ for country $i\left(u \geq u_{i 0}\right)$ by $u_{i}^{*}=\arg \max \left\{w_{i}(u) \mid u \varepsilon U, u \geq u_{i 0}\right\}$. The following proposition is a straightforward consequence of $\mathrm{A} 1$ and $\mathrm{A} 2$.

\footnotetext{
${ }^{13}$ As noted below, however, there may also be upward pressure by POs on the USO under liberalization, so the assumption of a minimal response by the USP is definitely subject to further analysis.
} 


\subsection{Proposition 2:}

Without loss of generality, assume that countries are ordered so that $\mathrm{u}_{10} \leq \mathrm{u}_{20} \leq \ldots \leq \mathrm{u}_{\mathrm{n} 0}$. Supposing A1 and A2 to hold, a solution $u^{*} \varepsilon U$ to the USO design problem (13) exists. Moreover, defining $\underline{\mathrm{N}}=\left\{\mathrm{k} \varepsilon \mathrm{N} \mid \mathrm{u}_{\mathrm{i} 0}<\mathrm{u}_{\mathrm{i}}^{*}\right\}$ :

(1) If $\underline{\mathrm{N}}=\emptyset$, then any multi-national USO $\mathrm{u}^{*} \varepsilon \mathrm{U}$ satisfying $\mathrm{u}^{*} \leq \mathrm{u}_{10}=\operatorname{Min}\left\{\mathrm{u}_{10}, \ldots\right.$, $\left.\mathrm{u}_{\mathrm{n} 0}\right\}$ is optimal;

(2) If $\underline{\mathrm{N}} \neq \emptyset$, let $\mathrm{k}=\operatorname{Max}\{\mathrm{i} \mid \mathrm{i} \varepsilon \underline{\mathrm{N}}\}$; there exists an optimal multi-national USO $\mathrm{u}^{*} \varepsilon$ $\mathrm{U}$ satisfying $\mathrm{u}^{*} \leq \mathrm{u}_{\mathrm{k}}^{*}$.

The proof of Proposition 2 is in the Appendix. The fact that an optimal solution exists to (13) follows from continuity and the fact that, by the structure of (13), such a solution $u^{*}$ can, without loss of generality, be assumed to belong to the compact interval:

(14) $\mathrm{u}_{10}=\operatorname{Min}\left\{\mathrm{u}_{10}, \ldots, \mathrm{u}_{\mathrm{n} 0}\right\} \leq \mathrm{u}^{*} \leq \operatorname{Max}\left\{\mathrm{u}_{1}^{*}, \ldots, \mathrm{u}_{\mathrm{n}}^{*}, \mathrm{u}_{\mathrm{n} 0}\right\}$

The intuition behind both assertions (i) - (ii) is that unimodality of $\mathrm{w}_{\mathrm{i}}$ implies that $\mathrm{w}_{\mathrm{i}}$ is non-increasing for $\mathrm{u}>\mathrm{u}_{\mathrm{i}}^{*}$. Thus, countries for which the USO lower bound $\mathrm{u}_{\mathrm{i} 0}$ exceeds $\mathrm{u}_{\mathrm{i}}^{*}$ would experience no improvement in welfare from increasing the multi-national requirement $\mathrm{u}$ beyond $\mathrm{u}_{\mathrm{i} 0}$ (since the country regulator would already insist on implementing a $u_{i}>u_{i 0}$ and since $u_{i 0}>u_{i}^{*}$ implies by unimodality that $w_{i}(u)<w_{i}\left(u_{i 0}\right)$, for $u$ $>\mathrm{u}_{\mathrm{i} 0}$ ). Only countries in $\mathrm{N}$ whose historical/minimal USO standard $\mathrm{u}_{\mathrm{i} 0}$ is below their country-specific welfare-optimal level $u_{i}^{*}$ would see any potential welfare improvement from a more constraining (higher) multi-national USO. Obviously, if there are no countries for which multi-national regulation would improve welfare, the optimal solution (as shown in (i)) is "hands off", or in the language of the EU "subsidiarty dominates". Note in this analysis (see (13)) that we are assuming each country's welfare is weighted equally.

It is useful to contrast the single-country results of section 2 with the multi-country analysis of this section. For an individual country, there is a simple trade-off: increasing the scope of the USO has an adverse effect on the PO's profit, therefore, prices must increase to satisfy the zero profit constraint. However, as increased prices induce additional entry; more regions are served by competitors. However, as noted in the context of the model of section 2, entry is not necessarily welfare enhancing because the uniform price constraint may induce inefficient entry. Thus, if for some historical reason, the USO level in a country is sub-optimal, increasing it by imposing a higher standard at a multinational level may induce inefficient entry.

It is worth noting in the context of the above design problem that we have assumed perfect information on the part of the multi-national regulator. A decentralized solution would be rather complicated, in that it would have to assure such feasibility conditions as breakeven operations for the USP, thereby avoiding a Graveyard Spiral. Under perfect information, appending such constraints to the above problem is straightforward. Indeed, unless subsidies were allowed, given our assumptions on the monotonicity of the operating 
constraint function $\Gamma_{\mathrm{i}}(\mathrm{u})$, the regulator would have to choose a USO scope satisfying the additional constraint $u \leq \operatorname{Min}\left\langle u_{i}^{B} \mid i \in N\right\rangle$, where $u_{i}^{B}$ is the maximum $u$ at which $\operatorname{USP}_{i}$ can still break even. Under conditions of incomplete information, the problem would be to simultaneously have each $\mathrm{USP}_{\mathrm{i}}$ reveal $\mathrm{u}_{\mathrm{i}}^{\mathrm{B}}$ and to then set $\mathrm{u} \varepsilon \mathrm{U}$ to satisfy the revealed constraints. If the multi-national regulator were allowed to employ subsidies, then this could be formulated as a standard mechanism design problem. ${ }^{14}$

\section{$4 \quad$ Implications and conclusions for multi-national USO design}

The above results provide some intuition on the interaction of USO design, profits and welfare. We address here three assumptions underlying the above results: 1) that no subsidies are allowed or required for the PO to remain financially viable; 2) the implicit assumption that quantified welfare benefits are available for the assessment of alternative USO designs; ${ }^{15}$ and 3 ) that POs and their national regulators will attempt to implement a minimal USO design, consistent with their historical practice (see Assumption A1 in the previous section). Let us briefly comment on each of these.

We have assumed explicitly that the USO chosen by the multi-national regulator is not so stringent as to require subsidies for the PO to remain financially viable. There are two issues here: first is the presumption that the multi-national regulator would not have the power to collect taxes or distribute subsidies; ${ }^{16}$ second is the broader issue of whether subsidies, either from the multi-national regulator or from within member countries, are ever desirable. On the second, several forms of subsidy mechanism are discussed in Crew and Kleindorfer (2000), but our general conclusion then and now is that such subsidies would lead to significant transaction costs in their administration ${ }^{17}$ and to inefficiencies, including massive rent-seeking by POs. Under competitive entry, and assuming asymmetric information between the POs and their national and multi-national regulators, subsidies would be a recipe for overstaffing, for misalignment of prices and costs and for other competitive ills. For these reasons, we argue that the USO should be paid for from revenues generated by the PO itself, based on commercial freedom implied by full market opening. ${ }^{18}$

On the second issue, at the time of writing, we know of no published attempt to evaluate the costs and benefits of the postal USO empirically. Agreed, some aspects of this

\footnotetext{
${ }^{14}$ As least in the European Union, it does not seem likely that the multi-national regulator (the European Commission) would be equipped with the ability to tax some USPs and provide subsidies to others. Thus, the usual approach to mechanism design is not likely to be feasible for the postal USO. The approach of referendum voting, essentially that proposed by Crémer-Palfrey, could be imagined as a model for the postal USO (with representative voting through the Parliament), but the ability of members of the European Council to veto regulations suggests that more of a consensus, bargaining model may be appropriate, given current governance in the EU. These are matters which we leave to future research.

${ }^{15}$ We are indebted to Regina Stöldt of the European Commission for raising this issue.

${ }^{16}$ In the postal sector for the EU, for example, this is currently the situation and this will very likely remain so as specific legislation would be needed to give the European Commission the necessary powers.

17 See PricewaterhouseCoopers (2006) for an extended discussion of some subsidy regimes in the EU, including appropriate restrictions based on the experience of using such schemes.

${ }^{18}$ In the event such subsidies are allowed, a joint design problem must then be solved, involving not just the scope of the USO but also the necessary restrictions on the structure and magnitude of subsidies.
} 
problem have been considered, such as the work of Reay (2002) and Crémer et al (1997) on service quality (one of the important attributes of the USO). However, the USO itself has been mostly the subject of political debates without any significant empirical assessments.

Consider the following issues. What is the value arising from the transaction-costs savings from pricing uniformity and access to post offices for different classes of customers? How many postal counters should there be in a country? What criteria should be used to assess their location? Should every counter in the country be equipped to offer the full range of services? If not, what range of services? Should the USO cover both First and Second Class mail? What other products should be a part of this? Should access products be included? Does the USO have elements of a public good (such as existence value), that is arising from its non-excludability and non-rivalrous aspects, that transcend the value that could be identified in principle from individual willingness-to-pay estimates? ${ }^{19}$ Each of these questions has had some airing in public debates about the USO, but we are far from having reasonable empirical assessments of these issues. Such assessments would require explicit knowledge of the various components of the welfare function posited in this analysis. It may be that competition will sort all of this out, making policy assessments unnecessary, but since USO decisions will almost certainly be made contemporaneously with liberalization choices, some benchmarks on the value of various USO design options would obviously be useful.

The third question raised above is whether national POs or their regulators would really press for the minimum USO scope consistent with historical trends (which perhaps represent some proxy for an efficient trade-off between the relevant costs and benefits of USO scope). In the opposite direction, there are several reasons to believe that, in some countries, there will be upward pressure on the USO, not downward pressure. Moreover, some of these pressures may be in the direction of self-serving rent seeking and not efficiency enhancing. ${ }^{20}$ For example, in the current debate on the USO in the European Union, several commentators seem to see a USO of broad scope as a means of maintaining the reserved area for some products for at least a further transition period. Others see a broad USO as desirable in facilitating adoption of subsidies for the PO after entry, as well as in legitimating other advantages (such as negotiated rather than mandated access prices) for the PO incumbent. Similarly, organized labor may use proposed reductions in the scope of the USO to rally the public to maintain an expanded scope to assure continuing levels of employment or to ward off increased requirements for flexible labor arrangements. ${ }^{21}$ As a further example of upward pressure in the EU, many countries continue to see their national PO exempt from Value Added Taxes (VAT) for USO services, even while potential competitors would face the requirement for collecting VAT. In this instance, the

\footnotetext{
${ }^{19}$ The issue of system-wide attributes of a USO has some relationship to the problem of reliability in other network industries. Attempts to value these network attributes have met a number of empirical and theoretical challenges, for example Hartman, Doane and Wu (1991).

${ }^{20}$ See Finger et al (2005) for a recent discussion of the pressures, pro and con, for reducing the scope of the USO in the European Union.

${ }^{21}$ Crémer and Palfrey (2000) provides a framework based on median-voter pressures that also predicts "federal" policies that will be stricter (that is, in the present context higher) than efficiency or local preferences would dictate. This arises in their model through the two-stage process of choosing a federal mandate, followed by local mandates that must be chosen to be at least as strict as the federal mandate. The postal USO context could very well succumb to the incentives to push for higher multi-national policies than desirable on efficiency grounds.
} 
broader the scope of the USO, the larger the revenues are that are protected (at least to the level of the VAT) from entry, since entrants would start with a disadvantage in pricing equal to the VAT in the respective country (on the range of $15 \%-20 \%$ in many EU countries). In such countries, it would not be a surprise to see continuing pressures for a broad USO. To the extent that the USO is, in fact, desirable from an efficiency perspective (that is, as measured by appropriately measured net benefits), it would naturally be required to provide the means to the Incumbent (and others in the market) to provide the USO and to achieve financial viability under liberalization. Clearly, some of these examples indicate forces other than a desire for greater efficiency.

These limitations, and others, suggest that caution must be exercised in drawing strong conclusions from this theoretical treatise on how to design multi-national USO policies. As with other important policy decisions, empirical research and understanding of the motivations of the stakeholders involved in any particular multi-national USO application would add considerably to the relevance and efficiency of the economic design and policy evaluation process.

\section{$5 \quad$ References}

Ambrosini, X., F. Boldron and B. Roy (2006) "Universal Service Obligations in the Postal Sector: Economic Learnings from Cross Comparisons," in M.A. Crew and P.R. Kleindorfer (ed.), Progress toward Liberalization of the Postal and Delivery Sector, Springer, New York.

Cohen, R.H., W.W. Ferguson, J.D. Waller, and S.S. Xenakis (2000) "Universal Service without a Monopoly," in M.A. Crew and P.R. Kleindorfer (ed.), Current Directions in Postal Reform, Kluwer Academic Publishers, Boston.

Cohen, R.H., M. Robinson, R. Sheehy, J.D. Waller and S. Xenakis (2004) "An Empirical Analysis of the Graveyard Spiral," in M.A. Crew and P.R. Kleindorfer (eds), Competitive Transformation of The Postal and Delivery Sector, Kluwer Academic Publishers, Boston.

Crémer, H., M. De Rycke and A. Grimaud (1997) "Service Quality, Competition and Regulatory Policies in the Postal Service," Journal of Regulatory Economics, 11: 5-19.

Crémer, J. and T.R. Palfrey (2000) "Federal Mandates by Popular Demand," Journal of Political Economy, 108: 905-927.

Crew, M.A. and P.R. Kleindorfer (1998) "Efficient Entry, Monopoly, and the Universal Service Obligation in Postal Service," Journal of Regulatory Economics, 14: 103-125.

Crew, M.A. and P.R. Kleindorfer (2000) "Liberalization and the Universal Service Obligation in Postal Service," in M.A. Crew and P.R. Kleindorfer (ed.), Current Directions in Postal Reform, Kluwer Academic Publishers, Boston.

Crew, M.A. and P.R. Kleindorfer (2001) "Whither the USO under Competitive Entry: A Microstructure Approach," in M.A. Crew and P.R. Kleindorfer (ed.), Future Directions in Postal Reform, Kluwer Academic Publishers, Boston. 
Crew, M.A. and P.R. Kleindorfer (2006) "The Welfare Effects of Entry and Strategies for Maintaining the USO in the Postal Sector," in M.A. Crew and P.R. Kleindorfer (ed.), Progress toward Liberalization of the Postal and Delivery Sector, Springer, New York

Crew, M.A. and P.R. Kleindorfer (2007) "Approaches to the USO under Entry," in M.A. Crew and P.R. Kleindorfer (ed.), Liberalization of the Postal and Delivery Sector, Edward Elgar Publishers, Cheltenham, UK.

d'Alcantara, G. and B. Amerlynck (2006) "Profitability of the Universal Service Postal Provider under Entry with Economies of Scale in Collection and Delivery," in M.A. Crew and P.R. Kleindorfer (ed.), Progress toward Liberalization of the Postal and Delivery Sector, Springer, New York.

De Donder, P., H. Crémer, and F. Rodriguez (2002) "Funding the Universal Service Obligation under Liberalization," in M.A. Crew and P.R. Kleindorfer (ed.), Postal and Delivery Services: Pricing, Productivity, Regulation and Strategy, Kluwer Academic Publishers, Boston.

Felisberto, C., M. Finger, B. Friedli, D. Krähenbühl and U. Trinkner (2006) "Pricing the Last Mile in the Postal Sector," in M.A. Crew and P.R. Kleindorfer (ed.), Progress toward Liberalization of the Postal and Delivery Sector, Springer, New York.

Finger, M., I. Alyanak and P. Rossel (2005) "The Universal Postal Service in the Communications Era: Adapting to Changing Markets and Customer Behaviour," College of Management of Technology, École Polytechnique Fédérale de Lausanne.

Haldi, J. and L. Merewitz (1997) "Cost and Returns from Delivery to Sparsely Settled Rural Areas," in M.A. Crew and P.R. Kleindorfer (ed.), Managing Change in the Postal and Delivery Industries, Kluwer Academic Publishers, Boston.

Haldi, J. and J.T. Schmidt (2002) "Saturday Delivery Who Provides It? Who Needs It? A Case for Alternative Delivery Strategies," in M.A. Crew and P.R. Kleindorfer (ed.), Postal and Delivery Services: Pricing, Productivity, Regulation and Strategy, Kluwer Academic Publishers, Boston.

Hartman, R.S., M.J. Doane and C.K. Wu, (1991) "Consumer Rationality and the Status Quo Bias,” Quarterly Journal of Economics, 106: 146-162.

Pintsov, L.A., A. Obrea and T. Biasi (2007) "Partitioning the Mailstream: Analysis of an Innovative Approach to USO," in M.A. Crew and P.R. Kleindorfer (ed.), Liberalization of the Postal and Delivery Sector, Edward Elgar Publishers, Cheltenham, UK.

PricewaterhouseCoopers (2006) The Impact on Universal Service of the Accomplishment of the Postal Internal Market in 2009. European Commission, Brussels (June). Available at http://ec.europa.eu/internal_market/post/studies_en.htm

Reay, I. (2002) "The Welfare Economics of Universal Service Standards and Service Quality," in M.A. Crew and P.R. Kleindorfer (ed.), Postal and Delivery Services: Pricing, Productivity, Regulation and Strategy, Kluwer Academic Publishers, Boston. 


\section{$6 \quad$ Appendix}

\subsection{Lemma 1}

Assume the regularity conditions $R C$. Let $U \subset \mathfrak{R}^{+}$be the set for which a solution $\mathrm{P}(\mathrm{u})$ to (2)-(3) exists and such that the profit function $\Pi(P(u), u)$ is locally increasing in $P$ at $P(u)$. Assume also that $\Pi^{*}=\operatorname{MAX}\langle\Pi(\mathrm{P}, 0) \mid \mathrm{P} \geq 0\rangle \geq 0$. Then $\mathrm{U}$ is a non-empty closed interval $\mathrm{U}$ $=[0, \overline{\mathrm{u}}]$, with

(A1) $\overline{\mathrm{u}}=\frac{\Pi^{*}}{\int_{0}^{\mathrm{T}} \mathrm{D}(\mathrm{t}) \mathrm{dt}}=\frac{\Pi^{*}}{\mathrm{Q}}$

Moreover, for any u $\varepsilon \mathrm{U}, \mathrm{P}(\mathrm{u})$ is unique and (strictly) monotonic increasing on $\mathrm{U}$.

Proof: Note that $\mathrm{t}_{\mathrm{I}}(\mathrm{P})$ is unique and well defined in (2), strictly increasing and continuous by strict montonicity and continuity of $\mathrm{CE}$. We first establish that the profit function is (strictly) unimodal under conditions $\mathrm{RC}(\mathrm{i})-\mathrm{RC}(\mathrm{iii})$. Since $\mathrm{t}_{\mathrm{I}}(\mathrm{P})$ is strictly increasing in $\mathrm{P}$, it suffices to show unimodality of the following transformed profit function in $t_{I}$ (obtained from (3) by substituting $\mathrm{P}=\mathrm{C}_{\mathrm{E}}\left(\mathrm{t}_{\mathrm{I}}\right)$ ):

(A2) $\pi\left(t_{I}, u\right)=\int_{t_{I}}^{T}\left(C_{E}\left(t_{I}\right)-C_{I}(\tau)\right) D(\tau) d \tau-u \int_{0}^{T} D(\tau) d \tau$

To show the unimodality of $\pi(t, u)$ for any fixed $u \varepsilon U$, compute first

(A3) $\frac{\partial \pi(t, u)}{\partial t}=\left[C_{I}(t)-C_{E}(t)\right] D(t)+\frac{d C_{E}(t)}{d t} \int_{t}^{T} D(\tau) d \tau$

Now note that the first term defining $\partial \pi / \partial \mathrm{t}$ is positive for $\mathrm{t}=0$. Moreover, since the second term defining $\partial \pi / \partial \mathrm{t}$ is always positive, $\partial \pi / \partial \mathrm{t}=0$ requires that $\mathrm{C}_{\mathrm{I}}(\mathrm{t})<\mathrm{C}_{\mathrm{E}}(\mathrm{t})$, so that any $t_{0}$ solving $\partial \pi / \partial t=0$ must satisfy $t>t^{*}$ in condition RC(i). Thus, for $t<t_{0}, \partial \pi / \partial t>0$ and for $\mathrm{t}>\mathrm{t}_{0}, \partial \pi / \partial \mathrm{t}<0$, that is $\pi(\mathrm{t}, \mathrm{u})$ is strictly unimodal in $\mathrm{t}$ for any $\mathrm{u}$ such that there exists a solution solving $\pi\left(\mathrm{t}_{\mathrm{I}}, \mathrm{u}\right)=0$ in (A2).

For the main assertion, consider any $\mathrm{u} \varepsilon \mathrm{U}$, so that there is a solution $\mathrm{P}(\mathrm{u})$ to (2)-(3) with $\Pi(\mathrm{P}, \mathrm{u})$ locally increasing in $\mathrm{P}$ at $\mathrm{P}=\mathrm{P}(\mathrm{u})$. Take any $\mathrm{u}^{\prime} \in \mathfrak{R}^{+}$satisfying $\mathrm{u}^{\prime} \leq \mathrm{u}$. From the definition of $\Pi(P, u)$, we see that

(A4) $\Pi\left(\mathrm{C}_{\mathrm{E}}(\mathrm{T}), \mathrm{u}^{\prime}\right)<0=\Pi(\mathrm{P}(\mathrm{u}), \mathrm{u})<\Pi\left(\mathrm{P}(\mathrm{u}), \mathrm{u}^{\prime}\right) \leq \Pi(\mathrm{P}(\mathrm{u}), 0) \leq \Pi^{*}$

so that continuity of $\Pi(\mathrm{P}, \mathrm{u})$ implies there exists a $\mathrm{P}\left(\mathrm{u}^{\prime}\right) \varepsilon\left[\mathrm{P}(\mathrm{u}), \mathrm{C}_{\mathrm{E}}(\mathrm{T})\right]$ satisfying $\Pi\left(\mathrm{P}\left(\mathrm{u}^{\prime}\right)\right.$, $\left.\mathrm{u}^{\prime}\right)=0$. From the unimodality of $\Pi(\mathrm{P}, \mathrm{u})$, it follows that, for $\mathrm{u}^{\prime} \leq \mathrm{u} \leq \overline{\mathrm{u}}$, there exists solutions $\mathrm{P}\left(\mathrm{u}^{\prime}\right) \leq \mathrm{P}(\mathrm{u}) \leq \mathrm{P}(\overline{\mathrm{u}})$ with $\Pi(\mathrm{P}, \mathrm{u})$ locally increasing in $\mathrm{P}$ at each such solution. 
(Note, by the definition of $\bar{u}$ and the profit function $\Pi(P, u)$, that $\bar{u}$ is the largest value of $u$ for which a solution to (3) exists.)

Finally, since $\Pi_{\mathrm{P}}(\mathrm{P}, \mathrm{u})>0$ at $\mathrm{P}=\mathrm{P}(\mathrm{u})$ for any $\mathrm{u}<\overline{\mathrm{u}}$, the strict monotonicity of $\mathrm{P}(\mathrm{u})$ follows from the Implicit Function Theorem (IFT) since from (3) and the IFT, $\partial \Pi$ / $\partial \mathrm{P}>0$ implies:

(A5) $\frac{\partial \Pi}{\partial \mathrm{P}} \frac{\mathrm{dP}}{\mathrm{du}}-\frac{\partial \Pi}{\partial \mathrm{u}}=0 \Rightarrow \frac{\mathrm{dP}}{\mathrm{du}}=\frac{\int^{\mathrm{T}} \mathrm{D}(\mathrm{t}) \mathrm{dt}}{\frac{\partial \Pi(\mathrm{P}, \mathrm{u})}{\partial \mathrm{P}}}>0$

from which the assertion follows.

\subsection{Proof of proposition 1}

The fact that $\mathrm{W}(\mathrm{P}, \mathrm{u})$ is well defined and continuous on $\mathfrak{R} \times \mathrm{U}$ follows from Lemma 1, from which the existence of an optimal solution $\left(\mathrm{P}^{*}, \mathrm{u}^{*}\right)$ follows directly. To show (9), note that $\mathrm{u}^{*}<\Pi^{*} / \mathrm{Q}$ follows since $\mathrm{u}^{*} \varepsilon \mathrm{U}=[0, \overline{\mathrm{u}}]=\left[0, \Pi^{*} / \mathrm{Q}\right]$. To show $\mathrm{u}^{*} \leq \sqrt{\mathrm{K} / \mathrm{Q}}$, note first that since the profit constraint is binding at the Ramsey optimal, it suffices in evaluating the optimal solution to consider the function $w(u)=W(P(u), u)$, with $P(u)$ the solution to (3) (which exists and is continuous by Lemma 1). Now note:

$$
\text { (A6) } \frac{d w}{d u}=\left[C _ { I } \left(t_{I}(P(u))-C_{E}\left(t_{I}(P(u))\right] D(P(u)) \frac{d_{I}}{d P} \frac{d P}{d u}-\left[Q-\frac{K}{u^{2}}\right]\right.\right.
$$

Since both $\mathrm{dt}_{\mathrm{I}} / \mathrm{dP}$ and $\mathrm{dP} / \mathrm{du}$ are positive by Lemma 1, the first term in (A6) has the sign of $\Delta(\mathrm{u})=\left[\mathrm{C}_{\mathrm{I}}\left(\mathrm{t}_{\mathrm{I}}(\mathrm{P}(\mathrm{u}))-\mathrm{C}_{\mathrm{E}}\left(\mathrm{t}_{\mathrm{I}}(\mathrm{P}(\mathrm{u}))\right]=\left[\mathrm{C}_{\mathrm{I}}\left(\mathrm{t}_{\mathrm{I}}(\mathrm{P}(\mathrm{u}))-\mathrm{P}(\mathrm{u})\right]\right.\right.\right.$ by $(2)$. But $\Delta(\mathrm{u})<0$ follows from (3) and RCi-iii since $\Delta(\mathrm{u}) \geq 0$ would imply $\mathrm{P}(\mathrm{u}) \leq \mathrm{C}_{\mathrm{I}}\left(\mathrm{t}_{\mathrm{I}}(\mathrm{P}(\mathrm{u}))<\mathrm{C}_{\mathrm{I}}(\mathrm{t}), \mathrm{t}>\mathrm{t}_{\mathrm{I}}(\mathrm{P}(\mathrm{u})\right.$, implying that $\Pi(\mathrm{P}(\mathrm{u}), \mathrm{u})<0$, a contradiction.

Knowing that the first term in (A6) is always negative, it follows that the Ramsey optimal $\mathrm{u} \varepsilon \mathrm{U}$ must occur where the second term $\left(\mathrm{Q}-\mathrm{K} /\left(\mathrm{u}^{2}\right)\right)$ is positive, from which $\mathrm{u}^{*} \leq \sqrt{\mathrm{K} / \mathrm{Q}}$ follows.

Concerning the first-order necessary conditions for the Ramsey problem, these are derived from the Lagrangian for the problem. Since there is one-to-one relationship between $t_{I}$ and $P$, with some abuse of notation, we state the optimization problem (5) in terms of the pair $\left(\mathrm{t}_{\mathrm{I}}, \mathrm{u}\right)$ as:

(A7) $\mathrm{L}\left(\mathrm{t}_{\mathrm{I}}, \mathrm{u}\right)=\mathrm{W}\left(\mathrm{t}_{\mathrm{I}}, \mathrm{u}\right)+\lambda \Pi\left(\mathrm{t}_{\mathrm{I}}, \mathrm{u}\right)$

where $\lambda>0$ is the dual variable associated with the profit constraint. From (A7), we have the following first-order conditions for (5):

(A8) $\left[\mathrm{C}_{\mathrm{I}}\left(\mathrm{t}_{\mathrm{I}}\right)-\mathrm{C}_{\mathrm{E}}\left(\mathrm{t}_{\mathrm{I}}\right)\right] \mathrm{D}\left(\mathrm{t}_{\mathrm{I}}\right)+\mathrm{kC}_{\mathrm{E}}^{\prime}\left(\mathrm{t}_{\mathrm{I}}\right) \int_{\mathrm{t}_{\mathrm{I}}}^{\mathrm{T}} \mathrm{D}(\mathrm{t}) \mathrm{dt}=0$ 
(A9) $u=\sqrt{\frac{\mathrm{K}(1-\mathrm{k})}{\mathrm{Q}}}$

where $\mathrm{k}=\lambda /(1+\lambda) \varepsilon(0,1)$. The fact that $\mathrm{k}>0$ follows from the fact (noted in the text) that the profit constraint is binding at the Ramsey optimum. The fact that $\mathrm{k}<1$ follows since $\lambda$ is finite. It is straightforward to show that the conditions (A8)-(A9) have a unique solution for any given constellation of costs and demands satisfying $\mathrm{RCi}$-iii. This follows by showing that $\mathrm{RCi}$-iii imply that the solution $\mathrm{t}_{\mathrm{I}}(\mathrm{k})$ to (A8) is increasing in $\mathrm{k}$, while the solution $u(k)$ to (A9) is clearly decreasing in $k$. The Ramsey solution results when $t_{\mathrm{I}}(\mathrm{k})$ as computed in (A8) equals the solution $\mathrm{t}_{\mathrm{I}}(\mathrm{u}(\mathrm{k})$ ) generated from (A9) and (2)-(3).

\subsection{Proof of proposition 2}

The existence of a solution to (3) is justified in the text. We consider claim (ii) first. Suppose there exists some $\mathrm{k} \varepsilon \mathrm{N}$ such that $\mathrm{u}_{\mathrm{k} 0}<\mathrm{u}_{\mathrm{k}}^{*}$ and $\mathrm{u}_{\mathrm{i} 0} \geq \mathrm{u}_{\mathrm{i}}^{*}$ for all $\mathrm{i}>\mathrm{k}$. Take any $\mathrm{u}$ $>\mathrm{u}_{\mathrm{k}}^{*}$; then reducing $\mathrm{u}$ to $\mathrm{u}_{\mathrm{k}}^{*}$ will not reduce aggregate welfare in (3). To see this, note that reducing $\mathrm{u}$ as indicated will not decrease any of the functions $\mathrm{w}_{\mathrm{i}}\left(\max \left(\mathrm{u}, \mathrm{u}_{\mathrm{i} 0}\right)\right), \mathrm{i} \geq \mathrm{k}$. For $\mathrm{i}=$ $\mathrm{k}$, this follows from the unimodality of $\mathrm{w}_{\mathrm{k}}$ and the assumption that $\mathrm{u}>\mathrm{u}_{\mathrm{k}}^{*}>\mathrm{u}_{\mathrm{k} 0}$. For $\mathrm{i}>\mathrm{k}$, we have two cases: either $\mathrm{u}>\mathrm{u}_{\mathrm{i} 0}>\mathrm{u}_{\mathrm{k}}^{*}$ or $\mathrm{u}>\mathrm{u}_{\mathrm{k}}^{*} \geq \mathrm{u}_{\mathrm{i} 0}$. In the first case, decreasing $\mathrm{u}$ to $u_{k}^{*}$ will result in the implementation of $u_{i}=u_{i 0}=\max \left(u_{k}^{*}, u_{i 0}\right)$ in country $i$, leading to an improvement in country i's welfare because of the unimodality of $\mathrm{w}_{\mathrm{i}}$. In the second case, $u$ $>\mathrm{u}_{\mathrm{k}}^{*} \geq \mathrm{u}_{\mathrm{i} 0}$, so that with our standing assumption that $\mathrm{u}_{\mathrm{i} 0} \geq \mathrm{u}_{\mathrm{i}}^{*}$ for all $\mathrm{i}>\mathrm{k}$, a decrease of $\mathrm{u}$ in the direction of $u_{i}^{*}$ will also imply a USO in country $i$ closer to its welfare optimal solution $u_{i}^{*}$. Thus, (ii) follows. If $\underline{N}$ is empty, case (i) of the Proposition, then it must be true that $\mathrm{u}_{\mathrm{i} 0} \geq \mathrm{u}_{\mathrm{i}}^{*}$ for all $\mathrm{i} \varepsilon \mathrm{N}$. In this case, any $\mathrm{u} \varepsilon \mathrm{U}$ which implies an increase in country i's USO beyond the historical level $u_{i 0}$ can only lead to a (further) decrease in country i's welfare. Since any solution that does not cause such an increase will lead to the enactment of its unconstrained USO $u_{i 0}$, any such solution would be optimal. Thus, (i) follows. 